Tesis 



\title{
Las armas en el Perú: una propuesta para el análisis sobre su regulación y control
}

\author{
Stephany Paola Recoba Vega
}

Ministerio de Trabajo y Promoción del Empleo, Lima, Perú

Recibido: 29/8/2018 / Aprobado: 16/2/2019

doi: 10.26439/iusetpraxis2018.n48-49.4507

Resumen. Entre los años 2014 y 2015, una de cada tres o cuatro armas de fuego de uso civil incautadas a la delincuencia correspondía a armas registradas en Sucamec. Este tipo de armas ocasiona más del 50 \% de las muertes en el Perú. En virtud de ello, si revisamos el marco legal e institucional relacionado con el control de la posesión de estas armas, se constata que su ineficacia se debe a que no forma parte del análisis de una política pública multisectorial.

PaLABRAS CLAVE: control institucional de armas de fuego / posesión de armas de fuego de uso civil / violencia armada / armas incautadas / políticas públicas / control de armas

Firearms in Peru: a proposal for analyzing its regulation and control

Aвstract. Between the years 2014 and 2015, one out of every three or four civilian firearms seized from criminals was registered in the National Superintendency for the Control of Security Services, Firearms, Ammunition and Explosives for Civilian Use (Sucamec). This type of arms causes more than $50 \%$ of deaths in Peru. In accordance with the aforementioned, by reviewing the legal and institutional framework regarding the control of firearm possession, it is determined that the inefficiency of such control is due to the lack of a public multisector policy.

KEYWORDS: institutional firearm control / civilian firearm possession / armed violence / seized firearms / public policies / firearms control 


\section{INTRODUCCIÓN}

El presente artículo es un resumen de las ideas principales de la tesis que sustenté en el 2018 en la Facultad de Derecho de la Universidad de Lima para optar al título de abogada. En su elaboración, conté con la asesoría del doctor José Ávila Herrera, por lo que me valgo de estas líneas para expresarle mi agradecimiento.

En el contexto actual de inseguridad ciudadana, es importante insertar en el debate público la necesidad de atención respecto a la circulación de las armas de fuego de uso civil y su control a través de medidas que tengan como objeto prevenir y reducir la violencia armada, en aras del bien común. En este sentido, cabe analizar la normativa peruana relacionada con la posesión de armas de fuego de uso civil, a fin de determinar si el marco legal e institucional ha resultado eficaz en el control de su posesión, que debe ejercer el Estado. Más aún, cuando la expansión del mercado legal de armas para uso civil representa un reto para la capacidad de control estatal.

Existe un amplio debate en diversos países acerca de la posibilidad del uso civil de armas de fuego, el cual es visto por muchos como un derecho o un privilegio que yace en un sistema permisivo o restrictivo. Cualquier análisis serio debe tener presentes los estándares o criterios considerados para el ejercicio de la posesión de armas de fuego, así como conocer la relación entre estas y los índices de violencia armada en América Latina y el Caribe. Todo ello sin dejar de lado el estudio de los instrumentos internacionales vigentes y el análisis comparativo de jurisdicciones como Guatemala, Argentina, Estados Unidos y Reino Unido, países interesantes de analizar de acuerdo con sus índices de violencia armada, la cantidad de armas de fuego de uso civil que poseen, además de la situación jurídica de cada uno de ellos.

En ese sentido, la investigación realizada aborda el problema de la falta de control de la posesión de las armas de fuego de uso civil. Para ello, analiza los cambios en la normativa peruana y la entidad encargada del control de armas de fuego civiles en nuestro país.

\section{¿EXISTE UN CONTROL INSTITUCIONAL EFICAZ DE ARMAS DE FUEGO DE USO CIVIL?}

El 17 de febrero del 2017, Eduardo Romero asesinó con un arma de fuego a tres personas e hirió a diez más en el distrito de Independencia, 
Lima. El arma de fuego contaba con una licencia vencida registrada en la Superintendencia Nacional de Control de Servicios de Seguridad Privada, Armas, Municiones y Explosivos de Uso Civil (Sucamec) ("Sucamec: 260000 personas tienen licencias de armas vencidas", 2017). Por su parte, el hospital San José del Callao declaró que no emitió un certificado de salud mental a favor Eduardo Romero, por lo que el documento que presentó sería presuntamente falso. Lo ocurrido con este certificado plantea la interrogante sobre si la institución que actualmente controla las armas civiles en el Perú se encuentra preparada para evaluar apropiadamente la originalidad de los documentos que constituyen requisitos para la emisión de licencias de armas. Por otro lado, el hecho de que existan 26000 licencias vencidas cuestiona la capacidad de la Sucamec para efectuar un control sobre armas que deberían contar con un registro vigente para su posesión y uso ("Sucamec: 260000 personas tienen licencias de armas vencidas", 2017).

Según los estudios realizados por la referida entidad, la cifra de armas incautadas a la delincuencia en el año 2015 es de 3960 armas de fuego, un $6 \%$ más respecto al año 2014; de estas, el $35 \%$ contaba con la serie erradicada, como el arma incautada a Jhairol Torres, quien fue detenido por el atentado contra Gerald Oropeza. A ello se suma una cifra del Instituto Nacional Penitenciario: 1992 internos, para el año 2015, tenían licencia para portar armas en el Perú (Briceño, 2015). Como se puede apreciar, las armas usadas para distintos crímenes siguen teniendo un registro en una entidad cuyo objeto es implementar filtros normativos que procuren la no desviación de las armas a la ilegalidad y, con ello, coadyuvar a la reducción de la violencia.

\section{Armas de fuego de uso civil Y Violencia armada}

De acuerdo con el artículo 16 del Reglamento de la Ley 30299, Ley de Armas de Fuego, Municiones, Explosivos, Productos Pirotécnicos y Materiales Relacionados de Uso Civil, aprobado mediante Decreto Supremo 010-2017-IN, de fecha 1 de abril del 2017, las armas de fuego para uso civil corresponden a las armas cortas o largas, como revólveres, pistolas, escopetas y carabinas, que no presentan la misma cadencia, calibre y potencia que las armas de uso militar o armas de guerra.

Los estudios sobre el uso de estas armas y su protagonismo en la proliferación de la violencia resultan aún escasos. Sin embargo, las 
investigaciones encontradas han señalado que las armas de fuego de uso civil no están vinculadas únicamente al crimen organizado, pandillaje o delincuencia común, sino también a conflictos interpersonales y domésticos. Por tanto, impactan en distintos niveles de la sociedad (Bacouillard, Guerrero y Bustamante, 2014). Al respecto, según el informe Carga global de la violencia armada 2015, elaborado por la Secretaría de la Declaración de Ginebra, en el mundo, las armas de fuego se utilizan en el $44,1 \%$ de todas las muertes violentas. Por otro lado, se estima que podrían haberse ahorrado aproximadamente dos billones de dólares de pérdidas económicas derivadas de los homicidios. Este monto equivale al 2,64 \% del PIB mundial en el año 2010.

Como vemos, la violencia armada tiene un alto costo humano y económico, y puede afectar a un país más que a otro. Y si bien nuestro país no ha alcanzado aún los niveles de violencia de otras regiones, el porcentaje de uso de armas de fuego en los homicidios aún es alto ${ }^{1}$ (Mujica, 2012).

Vale, entonces, partir de la concepción de que un millón de balas podría significar un millón de vidas. Y son esas armas las que se encuentran en manos de civiles. Una prueba de esto es que, en el año 2007, el estudio llevado a cabo por el Small Arms Survey calculó que el número de armas de fuego en manos de civiles en todo el mundo correspondía aproximadamente a 650 millones de armas sobre un total de 875 millones (Karp, 2011).

\section{LA NUEVA LEY DE ARMAS DE FUEGO DE USO CIVIL}

El artículo 19 de la Ley 30299, de fecha 22 de enero del 2015, establece un nuevo límite para los casos de defensa personal, que concede hasta tres armas si la circunstancia lo amerita. Sin embargo, no se precisa cuáles serían las circunstancias que permitirían esta cantidad de armas, lo cual configuraría un problema al evaluar la emisión de licencias de armas por parte de la Sucamec. En contraste con lo anterior, la misma ley señala que el número de armas de fuego destinadas para caza no

1 De acuerdo con el Comité Estadístico Interinstitucional de la Criminalidad (2016), en el período 2011-2015, el mayor porcentaje de muertes violentas asociadas a hechos delictivos dolosos fue ocasionado con arma de fuego. Desde el 2013, se ha evidenciado que el uso de armas de fuego ha disminuido (68,1 \% en el 2013; 65,3\% en el 2014, y 56,6 \% en el 2015); sin embargo, la utilización de armas de fuego de uso civil aún supera el $50 \%$. 
están sujetas a límite alguno y precisa únicamente que este tipo de armas de fuego pueden ser cortas o largas. Asimismo, establece que la prohibición del uso de silenciadores no alcanza a las armas destinadas para caza.

Teniendo en cuenta estas disposiciones, resulta relevante notar que el informe de armas incautadas en nuestro país del 2013 al 2015, elaborado por la Sucamec (2016), demuestra que, de todas las armas que la Policía Nacional del Perú decomisó a nivel nacional a la delincuencia, 1 de cada 3 o 4 armas era de uso civil y correspondía a una licencia expedida por la Sucamec. Cabe indicar que muchas de estas armas se encontraban relacionadas con armas de caza. Por lo tanto, se deben analizar los filtros o requisitos dispuestos para la emisión de licencias en la modalidad de caza, en vista de que dichas armas, así como sus accesorios, tales como los silenciadores, podrían pasar a la ilegalidad.

Respecto a las armas de fuego prohibidas para el uso civil, el antiguo Decreto Supremo 022-98-PCM, que aprobó el Reglamento que Norma la Entrega de Armas de Guerra, afirmaba que se consideran armas de guerra a las armas $9 \mathrm{~mm}$ Parabellum, debido a su calibre y potencia. Empero, la Ley 30299, a pesar de señalar que las armas de fuego de uso civil son distintas de las de guerra, no menciona, en su cuarta disposición complementaria transitoria, a las armas $9 \mathrm{~mm}$ Parabellum dentro de la clasificación de armas de uso militar. Al respecto, el Decreto Supremo 010-2017-IN ha derogado toda la regulación relacionada con la prohibición de este tipo de armas, lo que remite a cuestionar si dicha modificación normativa depende de la seguridad ciudadana o de intereses de ciertos stakeholders.

No obstante todo ello, debemos rescatar que esta nueva ley establece filtros que permiten ejercer un mejor control sobre el acceso a la posesión y uso de armas de fuego de uso civil. Así, su artículo 7 establece condiciones para la obtención y renovación de licencias y autorizaciones que no habían sido requeridas en anteriores cuerpos normativos.

\section{NeCESIDAd De CONTROL DESDE LA ÓPTICA DE UNA POLÍTICA Pública}

Es evidente que la expansión del mercado legal de armas para uso civil es un reto para la capacidad de control estatal. Entre 1980 y el 2015, la emisión de licencias de posesión y uso de armas de fuego de uso civil se ha incrementado de 839 a 46309 (Sucamec, 2016). 
Si analizamos las modificaciones normativas hasta antes de la Ley 30299 y las medidas actuales para contrarrestar los defectos del desempeño de, a decir verdad, muchas instituciones, podremos constatar que estas no han respondido a políticas públicas estructuradas a largo plazo, sino a eventos relacionados con hechos delictivos. De esa forma, se generan respuestas a corto plazo. Como señala el investigador Jaris Mujica, no solo la regulación en años anteriores ha sido negativa, sino también la labor de sistematización de información sobre armas de fuego, licencias y portadores de armas. Ello no permitía conocer la situación en que se encontraba el control de armas de fuego, pero sí denotaba las deficiencias de la entidad que llevaba a cabo dicho control (Subirana, 2017).

Y es que uno de los principales desafíos que enfrentan los países latinoamericanos relacionados con su seguridad se vincula a la necesidad de fortalecer sus propias instituciones [...]. Con relación a ello, los instrumentos interinstitucionales revisados señalan la necesidad de los Estados de adoptar las medidas necesarias para impedir que las armas de fuego se desvíen a la ilegalidad. (Dammert, 2010)

En ese sentido, una entidad estatal como una superintendencia necesita no solo un marco legal idóneo para el desarrollo de sus funciones, sino también la capacidad para hacer efectivas sus atribuciones de control, fiscalización y sanción, a fin de disuadir el incumplimiento de la normativa vigente. De ese modo, las medidas y los cambios normativos e institucionales de una entidad cuyo objeto de control son las armas de fuego - más aún si su nacimiento como superintendencia tiene, como una de sus causas, un diagnóstico institucional en el que se identificó que las áreas encargadas de la evaluación, emisión y control de la posesión de armas de fuego fueron las más proclives a prácticas de corrupción ${ }^{2}-$ deberían surgir como parte de un análisis propio de una política pública de seguridad ciudadana, que no solo contemple un control normativo, sino uno institucional. Así se podrán evaluar las razones de la escasa

2 En el año 2012, se inició un proceso de diagnóstico institucional en el sector Interior que identificó como problemas neurálgicos la eficiencia, la eficacia y la transparencia de servicios. Como resultado, se encontró que la Gerencia de Explosivos y Productos Pirotécnicos de Uso Civil; la Gerencia de Armas, Municiones y Artículos Conexos; la Gerencia de Control y Fiscalización, y la Gerencia de Servicios de Seguridad Privada eran las más proclives a prácticas de corrupción en un $63 \%, 61 \%, 58 \%$ y $57 \%$, respectivamente (Bazán Seminario y Levaggi Tapia, 2014, p. 10). 
capacidad que ha demostrado subsistir en el control de armas de fuego de uso civil, pese a los esfuerzos normativos que se implementan para reducir el desvío de estas armas a la ilegalidad.

\section{A manera de Conclusión}

Es necesario que nuestro país cuente con una política pública en materia del uso de armas, que tenga los siguientes objetivos:

- Adoptar un marco legal claro sobre los tipos de calibres autorizados y la cantidad de armas autorizadas, que se encuentre armonizado con la normativa internacional.

- Reformular los exámenes de salud mental para los usuarios de armas de fuego de uso civil.

- Regularizar las licencias de armas de uso civil a través de la identificación de existencias de armas a nivel nacional, programas de amnistías para el registro de armas de fuego en situación irregular y programas de entrega voluntaria de armas de fuego.

- Proveer sistemas registrales mediante el uso de tecnologías especializadas que permitan la actualización periódica de la base de datos correspondiente a armas de fuego y el intercambio de información interinstitucional.

- Mejorar la gestión de arsenales, lo que incluye implementar infraestructuras a nivel nacional que se adecúen a las recomendaciones internacionales y a la normativa vigente; así como la revisión periódica de esta infraestructura.

- Implementar un registro virtual donde los usuarios de armas a nivel nacional puedan actualizar sus datos periódicamente de acuerdo a ley; este registro puede tomarse de modelos existentes en otras instituciones de nuestro país, tales como el de la Superintendencia Nacional de Aduanas y de Administración Tributaria (Sunat).

- Efectuar campañas periódicas que tengan como finalidad disuadir a la población respecto al uso de armas de fuego; estas pueden realizarse a través de anuncios radiales y por redes sociales a fin de concientizar a los ciudadanos sobre los impactos negativos en factores económicos, culturales, sociales y ambientales, entre otros. 
Además, es de considerar que, en nuestro país, las alternativas para reducir el índice de violencia armada pueden incluir sanciones administrativas, civiles o penales, además de medidas de policía administrativa o medidas correctivas, las cuales tienen como objeto controlar la conducta de los particulares a efectos de cumplir con la normativa vigente. A estas medidas debería sumarse la implementación de programas que involucren la participación ciudadana y el análisis de la influencia que se tiene sobre los grupos de interés relacionados con las armas de fuego.

Cabe recordar, como señala Cornejo Álvarez (1997), que, a pesar de que el principio de legalidad de una entidad se base en la regulación y sus cambios, estos no serán suficientes en cuanto no converjan con la estructura, el proceso y los objetivos de una organización. En este caso, tales elementos comprenden varias entidades relacionadas directa o indirectamente con el control de armas de fuego, como el Ministerio Público, el Ministerio de Justicia, el Ministerio del Interior, el Ministerio de Salud, entre otros. En ese sentido, el abordaje de este problema reclama el diseño de políticas públicas específicas que reconozcan la complejidad de las causas y alcances de la violencia armada, por lo que se trata de una cuestión que atraviesa a todos los poderes del Estado y que debe encararse prestando atención a sus distintas dimensiones. La posibilidad de retirar las armas de fuego de aquellas situaciones de violencia es una intervención que no resuelve este tipo de conflictos, pero puede operar en la minimización de los daños (Comisión Provincial por la Memoria, 2015).

\section{REFERENCIAS}

Bacouillard, R., Guerrero, C. D., y Bustamante, J. (2014). Proliferación de armas y violencia armada en el sector de la seguridad privada en América Latina y el Caribe: desafíos y oportunidades para la acción. Policía y Seguridad Pública, 2(4), 31-79.

Bazán Seminario, C., y Levaggi Tapia, J. (2014). ¿Civiles armados? Análisis de las propuestas de modificación de la normativa sobre armas de uso civil en el Perú [documento de trabajo]. Lima: Instituto de Defensa Legal. Recuperado de https://www.academia.edu/11392509/_ Civiles_armados_An\%C3\%A1lisis_de_las_propuestas_de_modificaci\%C3\%B3n_de_la_normativa_sobre_armas_de_uso_civil_ en_el_Per\%C3\%BA 
Briceño A. (20 de junio del 2015). Casi dos mil presos tienen licencia para portar armas. El Comercio. Recuperado de https://elcomercio. pe/lima/dos-mil-presos-licencia-portar-armas-373176

Comisión Provincial por la Memoria. (2015). Prevención de la violencia armada en la provincia de Buenos Aires. Recuperado de http://www. pensamientopenal.com.ar/system/files/2015/10/miscelaneas42233.pdf

Cornejo Álvarez, A. (1997). Complejidad y caos. Guía para la administración del siglo Xxı. México D. F.: Juan Carlos Martínez Coll.

Dammert, L. (2010). Violencias, crimen e inseguridad en América Latina. Desafíos para la democracia. En L. Dammert (Ed.), Violencia e inseguridad ciudadana en las Américas. Lima: El Virrey.

Karp, A. (2011). Estimación de las armas de fuego en posesión de civiles. Small Arms Survey Research Notes, 9, 1-4.

Ley 30299, Ley de Armas de Fuego, Municiones de Fuego, Municiones, Explosivos, Productos Pirotécnicos y Materiales Relacionados de Uso Civil. (22 de enero del 2015). Recuperado del sitio de internet de Sucamec: https://www.sucamec.gob.pe/web/images/2016/ nueva_ley/LEY_ARMAS_EXPLOSIVOS_PIROTECNICOS_30299.pdf

Mujica, J. (2012). Armas pequeñas en el crimen urbano: delitos, acceso y mercados ilegales de armas de fuego en Lima. Lima: Clacso/Cusepa.

Subirana, K. (1 de marzo del 2017). El control de armas de fuego y su relación con la delincuencia. Punto Edu. Recuperado de https:// puntoedu.pucp.edu.pe/noticias/el-control-de-armas-de-fuego-ysu-relacion-con-la-delincuencia/

Sucamec: 260000 personas tienen licencias de armas vencidas. (18 de febrero del 2017). Gestión. Recuperado de https://gestion.pe/economia/sucamec-260-000-personas-licencias-armas-ven cidas-129008

Sucamec. (2014). Armas incautadas. Reporte 2013. Lima: Autor.

Sucamec. (2015). Armas incautadas. Reporte 2014. Lima: Autor.

Sucamec. (2016). Armas incautadas. Reporte 2015. Lima: Autor. 
